\title{
Link maps and map meetings: Scaffolding student learning
}

\author{
Christine Lindstrøm and Manjula D. Sharma \\ School of Physics, University of Sydney, New South Wales 2006, Australia
}

(Received 8 July 2008; published 22 January 2009)

\begin{abstract}
With student numbers decreasing and traditional teaching methods having been found inefficient, it is widely accepted that alternative teaching methods need to be explored in tertiary physics education. In 2006 a different teaching environment was offered to 244 first year students with little or no prior formal instruction in physics. Students were invited to attend additional enrichment classes $1 \mathrm{~h}$ a week called map meetings. The focus of these classes was a different type of visual presentation of physics material called link maps. Link maps explicitly show the key concepts covered in lectures and how these interrelate to help novices establish their physics schemata. In each map meeting the link map for the different topic was interactively discussed by the researcher before the students worked on problems in groups using the link map. The class ended with the researcher going through one problem, talking aloud about how to logically attack it. The results were promising. Each week about $20 \%$ of the class voluntarily attended map meetings whereas $22 \%$ reported that they did not attend due to timetable clashes. Two questionnaires revealed that students thought the classes were helpful for gaining an overview of physics and for developing their problem solving abilities. In the final examination the 32 students who had attended at least eight out of ten map meetings achieved, on average, 9 points out of 90 better in the examination $(p=0.004)$ than a comparison group $(N=40)$ with similar academic background which had not attended map meetings. The results of this study suggest that map meetings are a valuable learning environment for physics novices. Further investigations are currently being undertaken.
\end{abstract}

DOI: 10.1103/PhysRevSTPER.5.010102

PACS number(s): 01.40.Fk, 01.40.gb, 01.50.F-

\section{INTRODUCTION}

Physics education research is based on the premise that "the how and the what of learning are inseparable aspects of learning." Learning physics is concerned with gaining a sound understanding of a web of relatively few fundamental concepts and becoming well versed in the "when," "how," and "why" of their application. The complex process of developing analytical skills - such as logical reasoning, problem solving, and critical evaluation, which are skills in high demand by employers - is central to the subject. However, student numbers in physics are decreasing, ${ }^{2-4}$ and to make physics accessible to a greater proportion of the student population a range of teaching methods is being developed. ${ }^{5,6}$

The traditional lecture style familiar to most students has repeatedly been proven highly ineffective for conceptual understanding, ${ }^{7-10}$ yet it prevails as the central educational method. Alternative teaching methods, such as the modeling method, case study physics, and scale up, have shown significantly higher gains in student learning. $6,7,11$

This study explored an enrichment intervention within a teaching structure containing lectures, laboratory sessions, and tutorials. The primary researcher's reflections on her own learning experiences were merged with literature on learning theories to develop link maps, a physics-specific study aid, and map meetings, the environment for their implementation. In this paper we describe link maps and map meetings and address the following specific research questions:

(i) What fraction of students voluntarily attends map meetings, and what are their motivations?

(ii) How does the intervention affect students' attitudes toward physics? (iii) What effect does the intervention have on students' academic performance?

\section{THEORETICAL BACKGROUND}

The theory informing the design of link maps and the environment of their implementation is primarily drawn from the literature on concept maps, cognitive load theory, constructivism, and the model of domain learning.

Concept maps and knowledge maps are visual maps providing an overview of selected key concepts and their associations to aid schema formation. Such maps can also be used as diagnostic tools for evaluating whether associations have been formed to constitute meaningful schemata. The rules for their construction generally depend on their purpose as well as on subject area. ${ }^{12}$ Expert-made maps are generally the preferred use of this teaching aid when dealing with complex information and limited time, as the training process for students is lengthy and the mapping process is too difficult. ${ }^{13}$ In a study of the effectiveness of expert-made knowledge maps versus text in studying different medical procedures, Rewey et al. ${ }^{13}$ found that students using knowledge maps displayed a statistically significantly better recall of the main ideas, and a marginal significant difference $(p<0.07)$ in the recall of intermediate ideas. In another study investigating the value of communication aids in teaching, Patterson et $a l .{ }^{14}$ found that the retention of information was better for students taught using a knowledge map than for those using text. This result is believed to be due to the clear overview that such a map provides, as well as the reduced verbal content. In addition, knowledge maps have been proven useful as reference tools in problem solving. ${ }^{14}$ The use and success of visual maps are well documented in textually rich subjects such as biology, ${ }^{15}$ chemistry, ${ }^{16}$ and business. ${ }^{17}$ However, vi- 
sual maps have not been explored to the same extent as teaching aids in physics and mathematics.

To decide on the format for visual maps in physics, the nature of the subject had to be considered. Concept maps and knowledge maps follow fairly strict rules for their composition. Concept maps are read from top to bottom, moving from general to more specific concepts as one descends down the map. ${ }^{18}$ Knowledge maps, on the other hand, do not have this requirement of direction but rather consists of nodes with different verbal information interconnected with differentially nameable links. ${ }^{14}$ While these types of maps are good representations of textually rich subjects, for which they were developed, they would artificially constrain the representation of physics. It was important to us that the map structure was primarily informed by the natural structure of physics rather than by the established rules for existing types of maps not specifically developed for physics, even though this meant developing a new type of visual map.

A fundamental element of physics is that it already has a language with which to present sophisticated, involved, and profound ideas concisely and accurately-mathematics. Therefore, equations were an obvious feature to use in the visual maps. Naturally, this has not been the central feature of any other maps because few other subjects use mathematics as extensively as physics does. However, physics is not the same as mathematics. The real heart and beauty of physics lies in its simplicity: our physical world can be described using only a few unique constructs and the relationships between them. The structure of the field therefore lends itself perfectly to visual maps. Since this simplicity is by and large only apparent to experts, it was necessary that the maps be developed by experts. In addition to drawing on the concept map literature, the specific design features of the visual maps for physics, named link maps, were heavily based on cognitive load theory.

Cognitive load theory explains the limitations to learning imposed by the physical brain. It describes three types of memory, each with different functions and properties. In human interaction with the world the sensory memory works as a filter. Selected information proceeds to the working (or short-term) memory, where active cognitive processing takes place before being transferred to the long-term memory for retention. Whereas no upper limit to long-term storage capacity has been observed, the capacity of the working memory is severely limited. "Cognitive overload" refers to a situation in which a person tries to process more information than their working memory can handle (see recent review by van Merriënboer and Sweller). ${ }^{19}$ Only a few "chunks" of knowledge can be active at any one time, where a chunk represents a coherent set of knowledge with obvious internal associations. For example, to a physicist, force, mass, and acceleration constitute a chunk as they are clearly associated through Newton's second law. However, to a novice student, force, mass, and acceleration constitute three unrelated chunks, taking up a larger portion of the student's working memory. Strongly associated chunks make up schemata or mental models. ${ }^{12}$ These describe robust knowledge patterns that are associated across a variety of contexts, thus providing the framework for problem solving and logical reasoning. In this study working memory and mental models were considered when designing link maps and the sequence of peer collaborative tasks. In particular, the technique of "layering" (described in Sec. III) was developed to reduce students' cognitive load when presenting the link maps.

Once the link maps were designed, they needed to be implemented in an educational environment. Physics education research has shown that interactivity and meaning making must be facilitated for learning to occur. ${ }^{20}$ The design of the educational environment drew on the vast body of literature constructivism.

Constructivism has important implications for teaching and learning in which learners assimilate new knowledge within their existing knowledge schemata through active mental effort. ${ }^{21}$ The teacher is a facilitator rather than a transmitter, and the design of the instructional environment needs to scaffold the processes of schema development. Peer collaboration is particularly effective in schema development. By working together, relative novices can collaboratively manage to solve challenging learning tasks which none can do on their own. ${ }^{22}$ Such collaboration fosters "the acquisition of basic conceptual insight" 23 and has also been argued to be an important causal factor in the development of logical thinking. ${ }^{24}$ In this study, students worked in groups with the teacher scaffolding schema development and encouraging peer collaborative learning.

Although constructivism provides important guidelines when designing a learning environment, it does not elaborate upon the role motivation plays. There exists strong evidence that unless students' motivation is nurtured together with skill development, the performance gains are unlikely to be long lasting. ${ }^{25}$ The specific literature consulted for this study was that on the model of domain learning.

The model of domain learning (MDL) attempts to explain the journey from novice to expert in academic domains by considering the interplay of prior knowledge, interest, and strategic processing. ${ }^{26}$ The nature of each of these three factors changes markedly as the learner develops from novice, via competent learner, to expert, as do the features of the optimal methods of instruction. Experts within their domain have both breadth and depth of knowledge. To become an expert, the learner is generally highly motivated to persist with the subject. One of the most important fuels for motivation is interest, which is subsequently dependent on prior knowledge. ${ }^{27,28}$ For novices with limited and fragmented prior knowledge, motivation and interest need to be carefully considered. Hence, an important aspect of teaching novices is to motivate them by providing appropriate scaffolds such as good notes, adequate pacing, reducing assumption on prior knowledge, explicitly flagging important connections, developing learning strategies, and problem solving. ${ }^{29}$ The third factor, strategic processing, describes how students learn new material. Not only do different domains require different learning strategies, most expert strategies rely heavily on prior knowledge, ${ }^{18}$ rendering a large amount of strategic processing strategies unavailable to novice students. Focusing on novices, this study carefully considered students' levels of prior knowledge, interest, and strategic processing when developing link maps and map meetings.

This section has described the theoretical background which informed the development of link maps and map 


\section{DISPLACEMENT}

\section{ENERGY}

VELOCITY

\section{FORCE}

ACCELERATION

MASS

FIG. 1. The fundament sheet containing the seven fundamental concepts identified from the outline for the mechanics module.

meetings. Section III will explain in detail how the link maps were constructed and the environment in which they were implemented.

\section{LINK MAPS}

\section{A. Designing the link maps}

Link maps were designed using key ideas in physics and selected relationships constituting chunks that could gradually form the basis of a mental web structure (schema) over time and with use. Whereas concept maps generally focus on nodes and a myriad of associations, link maps were specifically developed with relatively few key concepts. These concepts are combined and dealt with differently depending on the topic and are also linked across different topics, reflecting the interconnectedness of the various fields in physics. The choice of just a few key ideas and relationships was intended to provide the first few tangible scaffolds to minimize cognitive overload. Students could grow diverse schemata on these tangible, but tentative scaffolds as their conceptual understanding developed.

Ten link maps were made, covering mechanics, hydrostatics, and waves. There was no standard layout of a link map except that all were based on more or less the same seven concepts: displacement, velocity, acceleration, force, energy, mass, and momentum, constituting a fundament sheet (see Fig. 1). These concepts were identified as central by perusing the course material and learning objectives. The cognitive load associated with getting to know a new map was likely reduced by building all maps "transposed" as close to the fundament sheet as possible.

Figure 2 shows the map covering Newton's laws. The map is divided into three sections, one for each law, and only force, mass, and acceleration from the fundament sheet are included. The map contains only the necessary information to describe the laws, the large arrows connecting any two laws make the relationships prominent, and simple diagrams help illustrate the physical scenario for each law.

\section{B. Implementing the link maps: Map meetings}

Link maps were implemented in 50 min enrichment tutorials called map meetings. Each map meeting summarized the topic covered in lectures in the previous week. The first 15-20 min were spent developing the link map. The researcher started with the fundament sheet on the overhead and atop it placed another transparency containing only a part of the link map [Fig. 3(a)]. The concepts and how they link were discussed interactively with the class. Next, a new transparency was overlaid the previous two [Fig. 3(b)], increasing the information on the map. As the information on

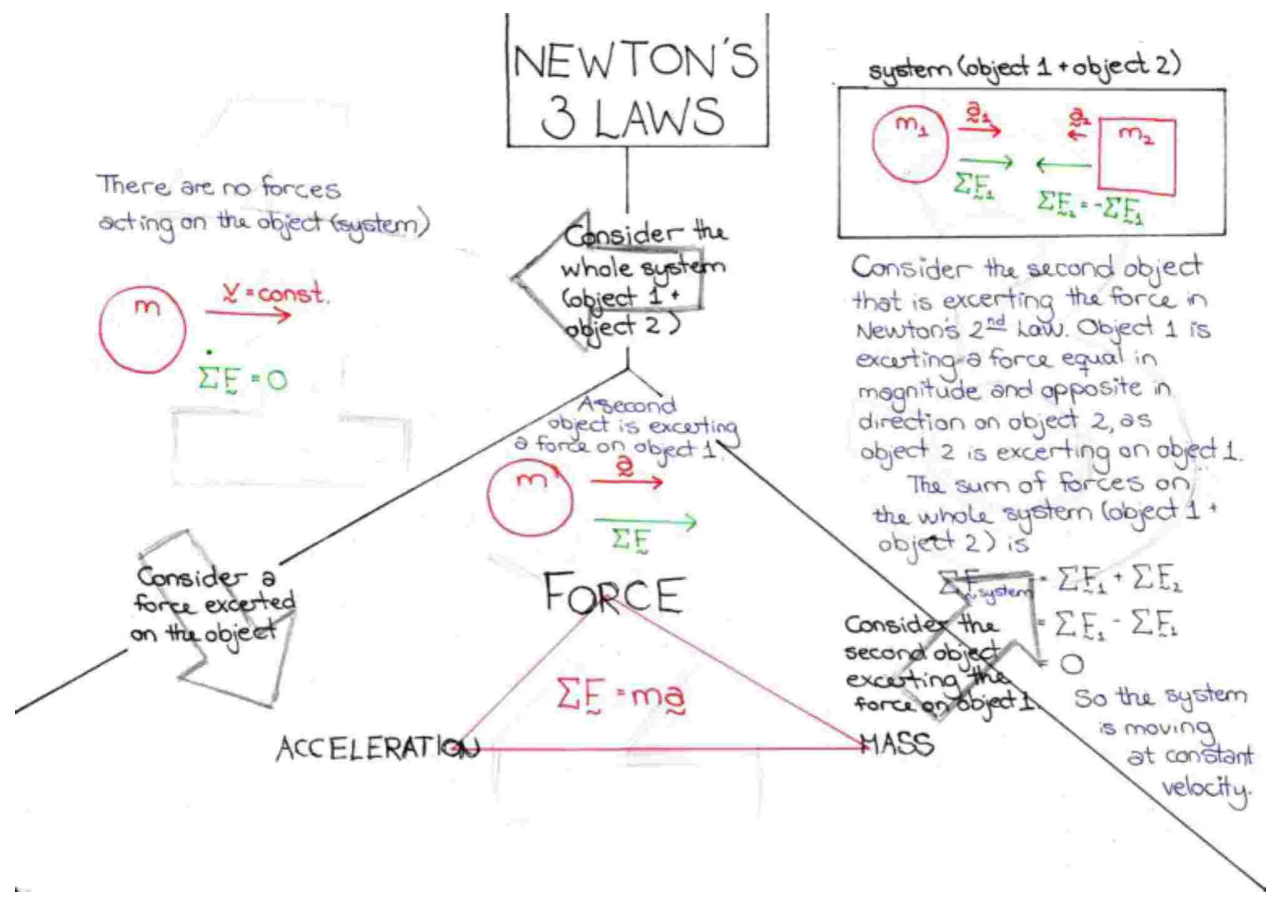

FIG. 2. (Color online) The link map covering Newton's three laws. 

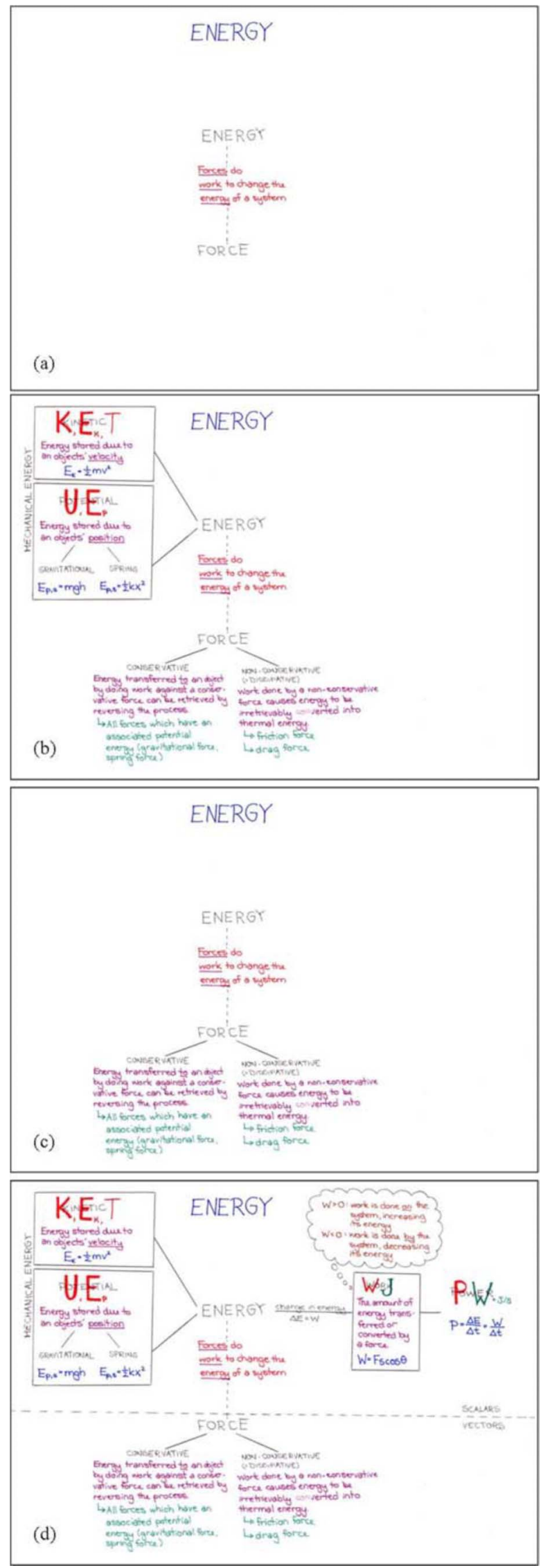

FIG. 3. (Color online) An illustration of the layering that was used to present the link maps in map meetings. the earlier transparencies had already been discussed, the students' attention was focused on the newly added information. This procedure was repeated until the link map was complete after four to six transparencies.

The above-described method is called layering, which was developed to mentally engage students during the process of constructing the map. The final map, in some cases, contained a considerable amount of information, but through layering, cognitive overload could be reduced as clear chunks were discussed in each layer. The process also allowed students to discern central ideas from peripheral knowledge and to make associations. During the layering process emerging understandings were explored interactively. When the map was complete the students were given a color paper copy of it.

In the second part of the map meeting $(15-20 \mathrm{~min})$ the students were given a problem sheet with two sections. The first section consisted of one or two simple many-part problems scaffolding the development of ideas. These problems were designed to develop the students' problem solving skills $^{30}$ and consolidate the link map. The questions were handwritten, making them less formal in line with the atmosphere of the map meetings. The second section had one or two past examination problems, giving students the opportunity to use the link maps while strategically processing the concepts and ideas. Students worked in collaborative groups of two to four students, with the researcher facilitating discussion.

In the last 10-20 min of each map meeting the researcher interactively explained problems students identified as challenging, taking students on the journey of logic. It was essential that the students had already attempted these questions in their peer groups. This philosophy was supported by studies showing that learning is most effective when explanations given are direct answers to student questions. ${ }^{31,32} \mathrm{At}$ the conclusion of the map meeting a complete set of handwritten solutions written by the researcher was handed out.

\section{METHOD}

The weekly map meetings were trialed in first semester, 2006, with first year students. Complete information for all students was unavailable, so the number of students contributing to any analysis will be quoted. The students had little or no prior experience with formal physics instruction [only $15 \%(N=146)$ had completed senior high school physics] and none enrolled was a physics major. Two hundred and forty four students were at some stage associated with the course, and 217 students sat the examination at the end of the semester. Individual student attendance in each tutorial was recorded. The students' university admission index (UAI) (an overall year 12 rank), individual year 12 subject scores, gender, and degree were obtained with informed consent.

Announcements were made and an information sheet handed out in class in the early weeks of semester inviting students to participate in an extra weekly contact hour called map meetings. Such treatments are termed "enrichment programs," which in this case involved no extra content. The sample was self-selected, making this study a quasiexperi- 


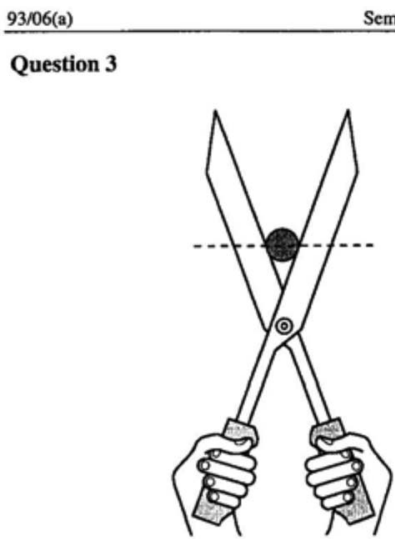

Position A

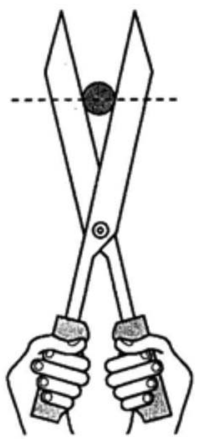

Position B Page 2 of 8 pages

Suppose you are trying to cut a branch of a tree using a pair of garden shears. Assume the blades are equally sharp at all positions along the blades.

Will it be easier to cut through the branch in Position A or Position B? Explain your answer in terms of the principles of physics.

(5 marks)

FIG. 4. Example of a past exam question handed out and worked on in class.

ment and resulting in some loss of control over the treatment variables. However, the strength of the study is the naturalistic setting.

Four identical 50 min map meetings were held each week; three were conducted by the primary researcher and one by the secondary researcher. Students could attend whichever map meeting suited their timetable and attendance was typically 10-20 students.

There were ten map meetings in total in the 13-week-long semester. The design and execution of both link maps and map meetings were continually improved throughout the semester, but the general structure was established by the fourth map meeting.

Two questionnaires (administered in lectures in weeks 4 and 13) and the final physics examination were used to evaluate the treatment. The return rates of the questionnaires for the student cohort were $49 \%$ and $45 \%$, respectively, which is considered adequate for sampling the diversity in the class. ${ }^{33}$ The questionnaires contained statements to which students agreed or not on a five-point Likert scale from strongly disagree (1) to strongly agree (5). The statements covered reasons for coming or not coming to map meetings, the usefulness of link maps, map meetings and other learning environments, and a few general questions probing students' attitudes toward physics. ${ }^{34}$ All statements are included in this paper, in either tables or figures. None of the items have been reversed for polarity, so statements must be read carefully.

The style of the examination is established and has been used as a diagnostic tool in previous studies. ${ }^{35,36}$ It is a threehour examination with six qualitative and six quantitative problems. The qualitative questions do not require any calculations; rather, they probe understanding of the physical problem at hand and request an answer linking relevant physical concepts and relationships, as illustrated in Fig. 4. The quantitative questions are always multipart questions requiring both calculations and qualitative reasoning (e.g., interpreting a numerical result or explaining an assumption). ${ }^{37}$

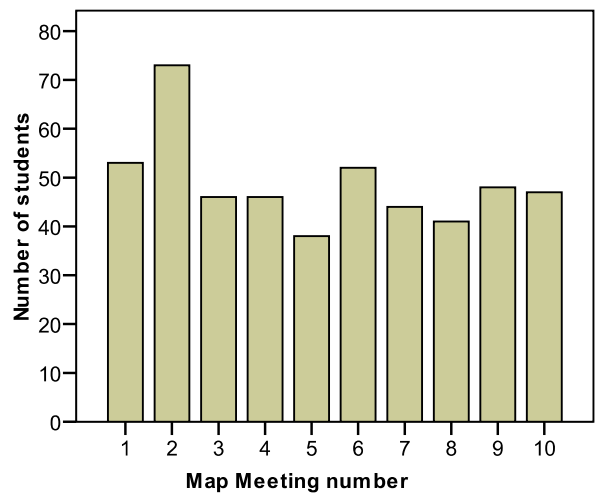

FIG. 5. (Color online) Weekly attendance at map meetings.

The emphasis on qualitative understanding and lack of multiple choice questions are reflective of the conceptual focus of the course. The examination was set by the lecturers and marked by faculty, not including the primary researcher.

\section{RESULTS: ANALYSIS AND INTERPRETATION}

\section{A. Attendance at map meetings}

There was no immediate reward for attending map meetings, yet attendance was relatively stable at roughly $20 \%$ of the class throughout the semester (see Fig. 5). According to questionnaire responses, the predominant reasons why students attended map meetings were to increase their confidence in physics and because they found them useful (Fig. 6). In response to why students did not attend map meetings (Fig. 7), 69\% ( $N=78)$ either agreed or strongly agreed to the statement that they could not make it to any of the four scheduled times. This is in agreement with the students, on average, disagreeing with all other suggested statements for why they did not attend. Of 22 students who had attended one map meeting, only one agreed to the statement that they found it a waste of time. Thus, map meetings were considered a valuable study opportunity. It is important to note that

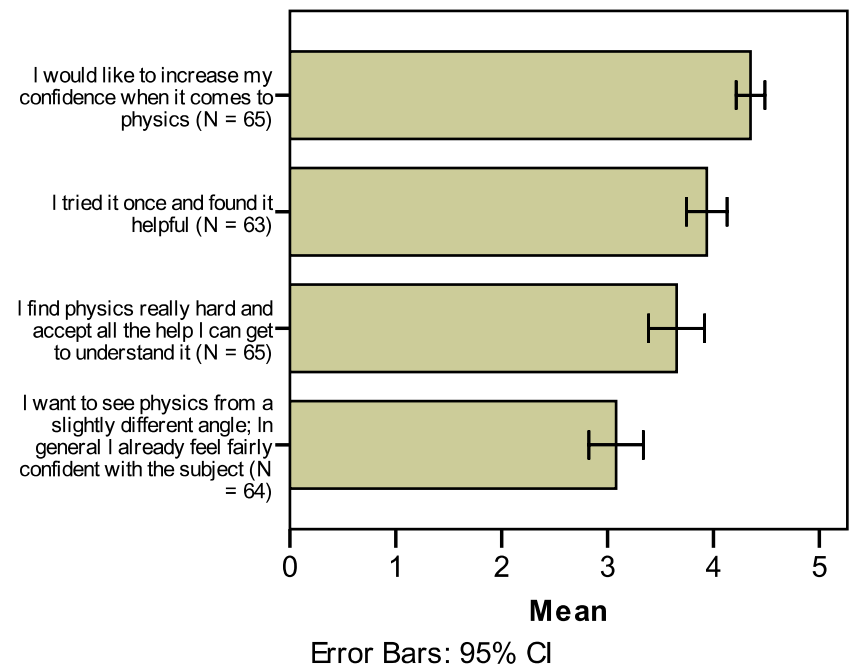

FIG. 6. (Color online) Student response to the statement "I come to map meetings because...." 


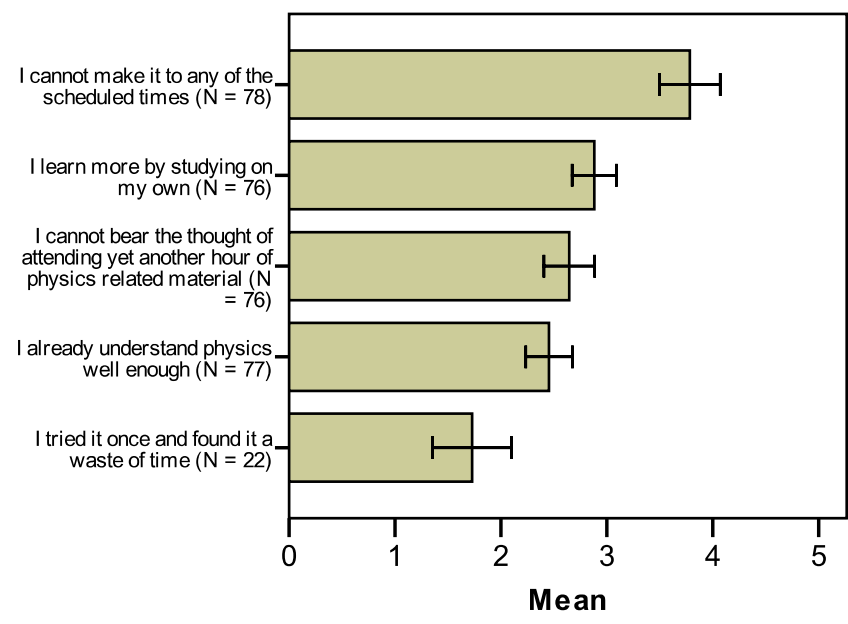

Error Bars: $95 \% \mathrm{Cl}$

FIG. 7. (Color online) Student response to the statement "I do not come to map meetings because...."

the reader may be concerned about a time on task issue and a volunteer bias in terms of which students took advantage of map meetings. The authors would like to point out that at this research intensive university students are expected to be independent and responsible for their own learning. It is not compulsory to attend lectures or tutorials (only laboratories), and an academic staff member (duty tutor) is available 8 $\mathrm{h} /$ week for students to consult in their own time. Students are also expected to study independently for $6 \mathrm{~h} /$ week. How students spend this independent study time is their own choice but commonly includes consulting the duty tutor or a private tutor, reading, solving problems, searching the internet for material, or attending map meetings. The amount of time spent studying is likely not affected by the offer of map meetings but only by the way students choose to spend this time.

To analyze the effect of the treatment two groups of "map meeters" were defined: persistent and non-map meeters. The persistent map meeters were students who had attended eight to ten map meetings, whereas non-map meeters had attended one or none. The effect on students who attended two to seven map meetings was expected to be highly variable, so this group was not considered. The non-map meeters are used in the analysis of attendance and attitudes toward physics, whereas subgroups with appropriate academic backgrounds will be defined and used when discussing examination performances.

\section{Why were link maps and map meetings useful?}

The physics course offers three learning environments: lectures, laboratories, and workshop tutorials. It is important to note that none of these environments can be considered "traditional." The lectures incorporate strategies ranging from interactive lecture demonstrations to classroom clickers, ${ }^{38,39}$ whereas the laboratory sessions include especially designed conceptual questions. Workshop tutorials, in particular, have previously been shown to be an effective learning environment. ${ }^{35,36}$ In addition, 12 review tutorials

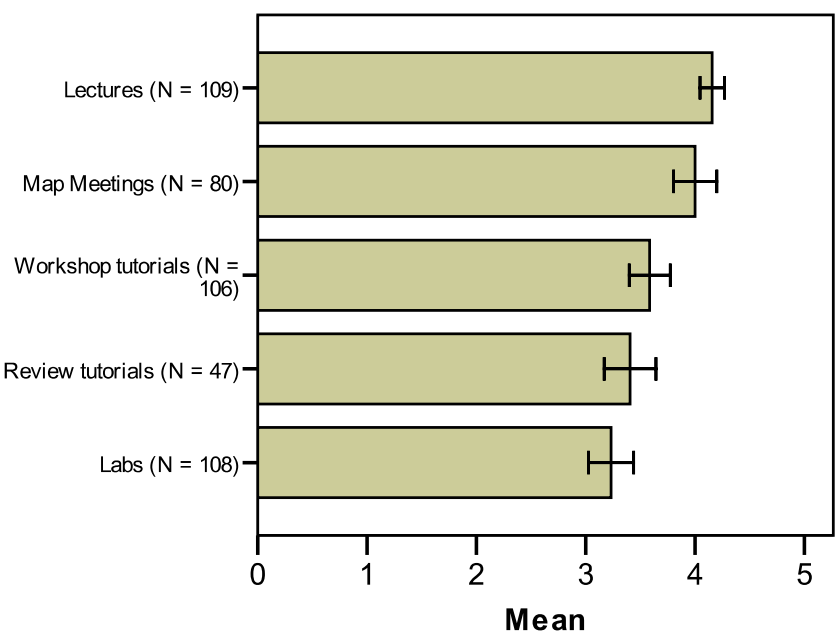

Error Bars: $95 \% \mathrm{Cl}$

FIG. 8. (Color online) Student response to "The following were useful for learning physics (only rate those you went to)."

over 4 weeks were offered at the end of the semester to help students at risk of failing. The student responses (Fig. 8) show that lectures and map meetings were considered the most useful environments for learning physics.

The following typical comment illustrates that these novice students found that the structure and coherency of link maps scaffolded their learning of ideas and associations.

Response to "What made map meetings worth coming to:"

"Simplified and condensed information in a much simpler language that was easy to understand. The diagrams and explanations for each rule helped explain what the key points were. The links [in the link maps] helped show relationships between concepts."

In their questionnaire responses, students agreed that all parts of the map meetings were helpful for learning physics (the map, the summary lecture, problem solving in groups and subsequently on the board, and receiving written solutions) (means 3.96-4.48, N=52 for all), indicating that the value of this project lies in the whole package of the map meetings, rather than just the link maps. As students put it

"[Map meetings] brought together a lot of muddled lecture info in a simple summary."

"Map meetings helped us go through things instead of just expecting us to understand all the hard stuff we'd done."

"Map meetings are really good. Now I have a confidence with physics. Thank you!"

"As a student who has never studied physics before, attending these meetings truly made physics easy."

In response to the statements,

"I found the maps useful...(1) for exam study, (2) in conjunction with reading through the course material, (3) while doing assignments, and (4) during lectures, laboratories and workshop tutorials," 
TABLE I. Descriptive statistics of the response from persistent map meeters to statements about map meetings.

\begin{tabular}{lccc}
\hline \hline & $N$ & Mean & SD \\
\hline $\begin{array}{l}\text { I think the maps are a valuable study aid } \\
\begin{array}{l}\text { The maps clarified what the key concepts } \\
\text { in physics are }\end{array}\end{array}$ & 4.52 & 0.59 \\
$\begin{array}{l}\text { I think I will do better in the exam because } \\
\begin{array}{l}\text { I went to map meetings } \\
\text { It was less intimidating to ask questions }\end{array}\end{array}$ & 4.60 & 0.58 \\
$\begin{array}{l}\text { in the map meetings } \\
\begin{array}{l}\text { I appreciated the atmosphere in the map } \\
\text { meetings }\end{array}\end{array}$ & 25 & 4.24 & 0.72 \\
\hline \hline
\end{tabular}

students agreed with all four (means 3.88-4.19, N=52 for all). This suggests that the maps were generally helpful in all aspects of physics learning.

The link maps themselves were often quite colorful and attempted to make clear the connection between concepts within each map as well as across maps. With a mean of 4.60 the persistent map meeters felt the following:

"The maps clarified what the key concepts in physics are" (Table I).

Even though the maps were rigidly structured around the fundament sheet, the researcher still exercised substantial freedom in constructing each week's map to present the information in the clearest and most concise way possible, which meant that maps could look quite different. Students did not seem to be confused by this lack of consistency and indicated that the maps indeed served their intended purpose.

"Link maps were very useful for linking the physics equations together, making it visual in colour. This technique was very useful for me to memorize most of the equations, and made it easier to understand the logic behind."

Students also found the following:

"Use of concept mapping was good because it allowed different topics within physics to be linked together."

Even though the map meetings presented topics in a simple way, the examination questions the students worked on were quite complex, providing valuable examination practice. When the researcher worked through the questions on the board, she not only gave the students the correct answer, but talked aloud about how to logically attack a complicated problem if they did not know where to start. The reason for doing this was that students, novices in particular, are well known to struggle with applying appropriate problem solving strategies, ${ }^{40}$ especially when they have little prior knowledge in a course focusing on conceptual understanding. ${ }^{41}$ The solution handouts were written in a similar way. This method is often not emphasized in lectures but was very well received by the map meeters.

"The problem solution handouts $(\cdots)$ helped me learn how to think logically before I attempt answering the question."

"Knowing that we could actually work exam questions out made me a lot more confident with physics."

The persistent map meeters also appreciated the atmosphere in the map meetings, which was nonstressful and friendly, and students felt less intimidated to ask questions (Table II),

"I was a lot more comfortable asking questions than in [workshop] tutorials where the teachers seem a lot less open to less intelligent questions."

Students also found it very helpful to cooperate with their peers in the problem solving session. This was similar to the peer collaboration in workshop tutorials, ${ }^{35}$ except that the self-selected students perhaps had a more positive attitude than the average student in workshop tutorials.

"Discussing questions as a small cooperative group [made map meetings worth coming to]. [Workshop] tutorials are not working for me because people in my group are not cooperative."

\section{B. Attitudes toward physics}

The attitude and examination data were analyzed using the statistical package for the social sciences (SPSS) (version 15.0). Normality was checked using the nonparametric onesample Kolmogorov-Smirnov test, and the appropriate parametric or nonparametric tests were consequently performed.

TABLE II. Student response to general questions about physics.

\begin{tabular}{|c|c|c|c|c|c|c|c|}
\hline & \multicolumn{3}{|c|}{ Persistent map meeters } & \multicolumn{3}{|c|}{ Non-map meeters } & \multirow[b]{2}{*}{ Sig. Mann-Whitney } \\
\hline & $N$ & Mean & SD & $N$ & Mean & SD & \\
\hline $\begin{array}{l}\text { Physics is about linking a few fundamental ideas } \\
\text { in several different ways }\end{array}$ & 23 & 3.96 & 0.77 & 58 & 3.62 & 0.70 & $0.030^{\mathrm{a}}$ \\
\hline $\begin{array}{l}\text { Physics is one of the most complicated subjects I } \\
\text { have ever studied (including high school subjects) }\end{array}$ & 25 & 3.60 & 1.19 & 60 & 3.08 & 0.98 & 0.054 \\
\hline $\begin{array}{l}\text { Physics is about remembering a lot of facts and } \\
\text { equations }\end{array}$ & 25 & 2.84 & 1.07 & 60 & 3.25 & 0.97 & $0.038^{\mathrm{a}}$ \\
\hline Studying physics is interesting & 25 & 3.68 & 0.95 & 60 & 3.22 & 0.89 & 0.016 \\
\hline
\end{tabular}

${ }^{\mathrm{a} O n e-t a i l e d ~ s i g n i f i c a n c e ~ d u e ~ t o ~ d i r e c t i o n a l ~ a s s u m p t i o n . ~}$ 
TABLE III. Descriptive statistics of the background of persistent map meeters and the similar and advanced groups.

\begin{tabular}{|c|c|c|c|c|c|c|c|c|c|}
\hline & \multicolumn{3}{|c|}{ Persistent map meeters } & \multicolumn{3}{|c|}{ Similar group } & \multicolumn{3}{|c|}{ Advanced group } \\
\hline & $N$ & Mean & $\mathrm{SD}$ & $N$ & Mean & SD & $N$ & Mean & SD \\
\hline UAI & 19 & 95.2 & 3.5 & 40 & 94.9 & 1.8 & 19 & 95.3 & 4.6 \\
\hline Basic math & 9 & 81.3 & 7.6 & 18 & 82.2 & 7.6 & & & \\
\hline Normal math & 11 & 89.7 & 3.1 & 22 & 88.8 & 3.4 & & & \\
\hline Advanced math & & & & & & & 19 & 88.0 & 4.4 \\
\hline Physics & & & & 4 & 84.5 & 3.8 & 4 & 80.8 & 5.0 \\
\hline
\end{tabular}

From Table II it can be seen that persistent map meeters agreed more strongly with the statement

"Physics is about linking a few fundamental ideas in several different ways"

than the non-map meeters. In addition, non-map meeters were somewhat positive to the statement

"Physics is about remembering a lot of facts and equations"

while the persistent map meeters were on the negative side. This suggests that map meetings were successful in teaching physics as a coherent and structured subject rather than one suitable for rote learning. By the end of the semester persistent map meeters found physics more interesting than the non-map meeters and believed that they would perform better in the final examination due to attending map meetings (Table I),

"I'm pretty sure I will pass...I'm just not very confident with myself-you gave me confidence."

\section{Final examination}

\section{Treatment and comparison groups}

The persistent and the non-map meeters did not have comparable high school backgrounds. Consequently, two subsets of the non-map meeters were chosen for analysis based on mathematics background and UAI, factors found to be predictors of academic achievement in physics. ${ }^{42}$

The similar group comprised all non-map meeters with UAI $\geq 91$ without advanced high school mathematics. These students did not have statistically significantly different UAI and mathematics background compared to the persistent map meeters, but $10 \%$ did have a physics background (Table III). The similar group was therefore considered somewhat stronger academically than the persistent map meeters. The advanced group was composed of the 19 students who had done advanced mathematics and could be considered the most advantaged group in the class.

\section{Total examination score}

The persistent map meeters achieved a statistically significantly higher average examination score than the similar group $[t(69)=2.95$ and $p=0.004]$ with a large effect size of $d=0.72 .{ }^{43}$ Furthermore, the persistent map meeters were on par with the advanced group (Fig. 9). In a similar study looking at the effectiveness of workshop tutorials, Sharma et $a{ }^{35}$ found effect sizes ranging from $d=0.15$ to 0.45 . In addition, none of the persistent map meeters failed, a feat not seen in either of the comparison groups.

\section{Detailed analysis of examination questions}

The qualitative and quantitative examination questions were categorized into the seven topics covered in chronological order in map meetings (Table IV). Figure 10 shows a

TABLE IV. Overview of topics covered in map meetings and the examination. The second map meeting covered symbols and units only, and hence did not belong to a specific topic.

\begin{tabular}{lcccc}
\hline \hline & $\begin{array}{c}\text { Qualitative } \\
\text { question } \\
(10 \text { points })\end{array}$ & $\begin{array}{c}\text { Quantitative } \\
\text { question } \\
(5 \text { points })\end{array}$ & $\begin{array}{c}\text { Covered in map } \\
\text { meeting number }\end{array}$ & $\begin{array}{c}\text { Examination } \\
\text { question }\end{array}$ \\
\hline Buoyancy & $\checkmark$ & $\checkmark$ & 1 & 1,7 \\
Linear motion & $\checkmark$ & $\checkmark$ & $3,4,5$ & 2,8 \\
Rotational motion & $\checkmark$ & $\checkmark$ & 6 & 4,9 \\
Energy and work & & $\checkmark$ & 7 & 10 \\
Linear momentum & $\checkmark$ & & 8 & 3 \\
$\begin{array}{l}\text { Simple harmonic } \\
\text { motion and waves }\end{array}$ & $\checkmark$ & $\checkmark$ & 10 & 5,11 \\
Traveling waves & $\checkmark$ & $\checkmark$ & & 6,12 \\
\hline \hline
\end{tabular}




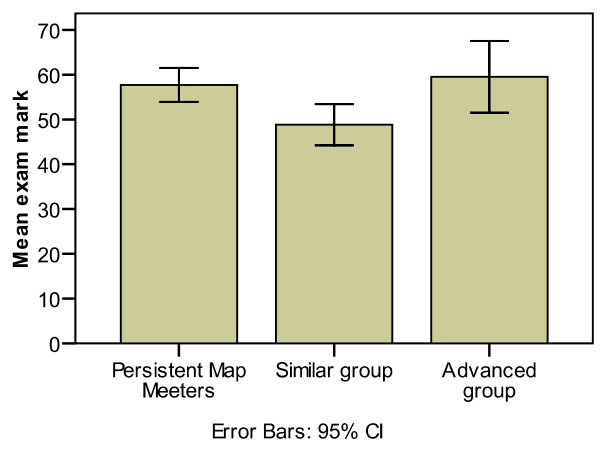

FIG. 9. (Color online) Mean total exam score for the persistent map meeters and the similar and advanced groups.

question by question comparison of average scores for the different groups. Some clear patterns emerge. The advanced group performed consistently better than the similar group except in question 12 (E12 in Fig. 10). The persistent map meeters changed from performing worse than the advanced group in the first two topics, to being reasonably close in the next three topics, and then performing much better in the last two topics. This student improvement mirrors the improvement of map meeting design and execution throughout the semester.

It is particularly interesting to note that in question 6 (E6 in Fig. 10) on thin-film interference, which had not been covered in map meetings, the persistent map meeters outperformed both the similar and advanced groups. To understand this observation we note that link maps carefully explored superposition of waves and phase change. Seemingly, this exploration provided the associations needed for students to answer the question. This strengthens the claim that the map meetings truly helped students gain a better understanding of the topics on a more fundamental level. We note that previous years examination questions are freely available to all students via the web and the researcher did not know the content of the examination until after all students had completed the examination.

\section{CONCLUSION}

The students who took advantage of map meetings were dedicated students, willing to commit themselves to another hour of physics study per week. This means that we cannot decouple persistence, motivation, and time on task. However, recall that a large proportion of the class indicated that they were unable to attend due to timetable clashes, so the distinction between persistent and non-map meeters is not simply conscientious versus lazy. Student feedback indicated that map meetings (together with lectures) were considered the most useful environment for learning physics. According to cognitive load theory, this structured learning environment provides necessary scaffolding, whereas constructivism emphasizes how the collaborative problem solving supports meaning making. ${ }^{13,14}$

By the end of the semester the persistent map meeters saw physics as a subject which links a few fundamental ideas in different ways rather than focuses on rote learning equations.

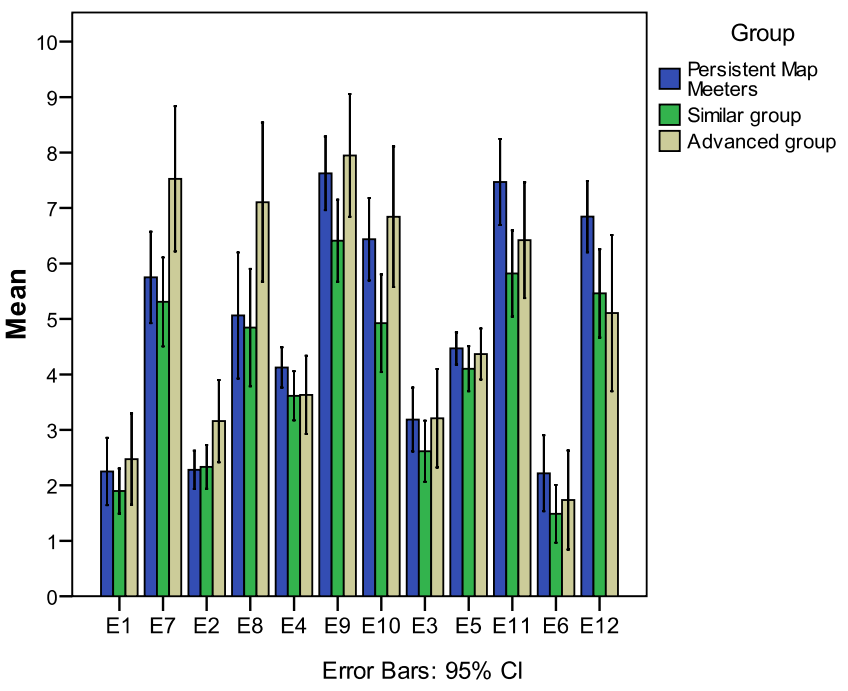

FIG. 10. (Color online) The exam broken down by questions. The topics covered in the exam are displayed in the sequence they were covered in the map meetings (cf. Table IV), such that the $x$ axis represents a timelike scale. Note that the persistent map meeters improve with respect to the similar and advanced groups as the semester progresses.

These views were statistically significantly different to students who had not attended map meetings.

The analysis of examination scores shows that the persistent map meeters performed remarkably well. An obvious question is whether this was due to the treatment or because the self-selected group studied harder. We note that the persistent map meeters received on average 9 points (out of 90) more than the similar group, even though these had comparable backgrounds. In fact, the persistent map meeters performed on par with the advanced group, which was considered to have the strongest background of the entire student cohort.

In summary, these findings strongly suggest that map meetings were successful in providing an effective learning environment and warrant further investigation. The weakness of this study was the lack of randomly sampled treatment and control groups. However, this was unavoidable due to the ethical considerations involved; the quality of the tutorial environment offered could not be compromised by randomly allocating students to the two different tutorial types, rendering volunteer attendance at map meetings the only option.

The key strength of the study was the naturalistic setting allowing the value of link maps and map meetings to be demonstrated. The study was strengthened further by employing a mixed method approach using both qualitative and quantitative measures, allowing results to be confirmed in different ways. Standard conceptual tests such as the Force and Motion Conceptual Evaluation (FMCE) ${ }^{44}$ and the Force Concept Inventory $(\mathrm{FCI})^{8}$ were not used as the qualitative questions in the end of semester examination are designed to probe conceptual understanding.

After the success of the study, it was no longer considered unethical to conduct a true experiment investigating the effectiveness of link maps and map meetings on learning 
physics. Therefore, a large-scale trial with random sampling is currently being undertaken. Analyses of this experiment will allow us to more accurately establish which type of student benefits from the treatment and if the findings from the study translates to the whole student population. It will also aid in further developing the theory and mechanisms underlying link maps and map meetings. Plans for further research are to narrow down the specific contributions of the various aspects of the treatment and ultimately to add to the understanding of how novice students learn physics and how we, as educators, can best facilitate their journey of knowledge construction.

\section{ACKNOWLEDGMENTS}

The authors would like to thank the Sydney University Physics Education Group for valuable discussions and comments of drafts of the paper, as well as the anonymous reviewer who provided extensive feedback which significantly helped to improve the paper.
${ }^{1} \mathrm{P}$. Ramsden, Improving teaching and learning in higher education: The case for a relational perspective, Studies in Higher Education 12, 275 (1987).

${ }^{2}$ S. Tobias and F. A. J. Birrer, Who will study physics, and why?, Eur. J. Phys. 20, 365 (1999).

${ }^{3}$ Mapping Physics Students in Europe (MAPS), a study undertaken by the European Physical Society (EPS), 2004 http:// ec.europa.eu/research/conferences/2004/sciprof/cd/pdf/extra/ maps_abstract_en.pdf.

${ }^{4} \mathrm{M}$. Alarcon, Physics without tears, A World of Science (UNESCO Newsletter) 3, 2 (2005).

${ }^{5}$ A. Mayo, M. D. Sharma, and D. A. Muller, Qualitative differences between learning environments using videos in small groups and whole class discussions: A preliminary study in physics, Res. Sci. Educ. (in press, 2008).

${ }^{6}$ J. Handelsman, D. Ebert-May, R. Beichner, P. Bruns, A. Chang, R. DeHaan, J. Gentile, S. Lauffer, J. Stewart, S. M. Tilghman, and W. B. Wood, Scientific Teaching, Science 304, 521 (2004).

${ }^{7}$ M. Wells and D. Hestenes, A modeling method for high school physics instruction, Am. J. Phys. 63, 606 (1995).

${ }^{8}$ D. Hestenes, M. Wells, and G. Swackhamer, Force concept inventory, Phys. Teach. 30, 141 (1992).

${ }^{9}$ D. Hestenes and M. Wells, A mechanics baseline test, Phys. Teach. 30, 159 (1992).

${ }^{10} \mathrm{~S}$. Tobias, They're Not Dumb, They're Different: Stalking the Second Tier (Research Corporation, Tuscon, AZ, 1994).

${ }^{11}$ A. Van Heuvelen, Overview, case study physics, Am. J. Phys. 59, 898 (1991).

${ }^{12}$ J. D. Novak, Learning, Creating, and Using Knowledge: Concept Maps as Facilitative Tools in Schools and Corporations (Erlbaum, Mahwah, NJ, 1998).

${ }^{13}$ K. L. Rewey, D. F. Danserau, L. P. Skaggs, R. H. Hall, and U. Pitre, Effects of scripted cooperation and knowledge maps on the processing of technical material, J. Educ. Psychol. 81, 604 (1989).

${ }^{14}$ M. E. Patterson, D. F. Danserau, and D. Newbern, Effects of communication aids and strategies on cooperative teaching, J. Educ. Psychol. 84, 453 (1992).

${ }^{15}$ F. N. Keraro, S. W. Wachanga, and W. Orora, Effects of cooperative concept mapping teaching approach on secondary school students' motivation in biology in Gucha District, Kenya, Int. J. Sci. Math. Educ. 5, 111 (2007).

${ }^{16}$ P. G. Markow and R. A. Lonning, Usefulness of concept maps in college chemistry laboratories: Students' perceptions and effects on achievement, J. Res. Sci. Teach. 35, 1015 (1998).

${ }^{17}$ L. A. Freeman and L. M. Jessup, The power and benefits of concept mapping: measuring use, usefulness, ease of use, and satisfaction, Int. J. Sci. Educ. 26, 151 (2004).

${ }^{18}$ J. D. Novak, Learning, Creating, and Using Knowledge; Concept Maps as Facilitative Tools in Schools and Corporations (Lawrence Erlbaum Associates, Mahwah, NJ, 1998).

${ }^{19}$ J. J. G. van Merriënboer and J. Sweller, Cognitive load theory and complex learning: Recent developments and future directions, Educ. Psychol. Rev. 17, 147 (2005).

${ }^{20}$ C. E. Wieman and K. Perkins, Transforming Physics Education, Phys. Today 58, 36 (2005).

${ }^{21}$ E. F. Redish, A theoretical framework for physics ecucation research, in Proceedings of the International School of Physics, "Enrico Fermi" Course CLVI, edited by E. F. Redish and M. Vicentini (IOS Press, Amsterdam, 2004), pp. 1-64.

${ }^{22}$ W. Damon and E. Phelps, Critical distinctions among three approaches to peer education, Int. J. Educ. Res. 13, 9 (1989).

${ }^{23}$ W. Damon and E. Phelps, (Ref. 23), p. 14.

${ }^{24} \mathrm{E}$. Forman, The role of peer interaction in the social construction of mathematical knowledge, Int. J. Educ. Res. 13, 55 (1989).

${ }^{25} \mathrm{H}$. W. Marsh and R. G. Craven, Reciprocal effects of self-concept and performance from a multidimensional perspective; beyond seductive pleasure and unidimensional perspectives, Perspective on Psychological Science 1, 133 (2006).

${ }^{26} \mathrm{P}$. A. Alexander, The development of expertise: The journey from acclimation to proficiency, Educ. Res. 32, 10 (2003).

${ }^{27}$ P. A. Alexander, J. M. Kulikowich, and S. K. Schulze, How subject-matter knowledge affects recall and interest, Educ. Res. 31, 313 (1994).

${ }^{28}$ P. A. Alexander, P. K. Murphy, B. S. Woods, K. E. Duhon, and D. Parker, College instruction and concomitant changes in students' knowledge, interest, and strategy use: A study of domain learning, Contemp. Educ. Psychol. 22, 125 (1997).

${ }^{29}$ M. Pressley, L. Yokoi, P. van Meter, S. Van Etten, and G. Freebern, Some of the reasons why preparing for exams is so hard: What can be done to make it easier?, Educ. Psychol. Rev. 9, 1 (1997).

${ }^{30}$ P. B. Kohl and N. D. Finkelstein, Patterns of multiple representation use by experts and novices during physics problem solving, Phys. Rev. ST Phys. Educ. Res. 4, 010111 (2008).

${ }^{31} \mathrm{~N}$. Webb, Task-related verbal interaction and mathematics learning in small groups, J. Res. Math. Educ. 22, 366 (1991).

${ }^{32}$ J. Sweller and G. A. Cooper, The use of worked examples as a substitute for problem solving in learning algebra, Cogn. Instruct. 2, 59 (1985)

${ }^{33}$ W. L. Neuman, Social Research Methods, Qualitative and Quantitative Approaches (Allyn and Bacon, Boston, MA, 2003).

${ }^{34}$ The authors are aware of the University of Maryland Physics Expectations Survey (MPEX) for probing student attitudes about 
physics. However, we decided to only create a few items on the questionnaire specifically targeting attitudes related to the treatment in this study, for which the items on the MPEX survey were not ideal.

${ }^{35}$ M. D. Sharma, R. Millar, and S. Seth, Workshop tutorials: Accommodating student-centred learning in large first year university physics classes, Int. J. Sci. Educ. 21, 839 (1999).

${ }^{36}$ M. D. Sharma, A. Mendez, and J. W. O'Byrne, The relationship between attendance in student-centered physics tutorials and performance in university examinations, Int. J. Sci. Educ. 27, 1375 (2005).

${ }^{37}$ M. D. Sharma, I. M. Sefton, M. Cole, A. Whymark, R. M. Millar, and A. Smith, Effects of re-using a conceptual exam question in physics, Res. Sci. Educ. 35, 447 (2005).

${ }^{38}$ H. M. Johnston, A. M. Hopkins, K. E. Varvell, M. D. Sharma, and R. Thornton, The research-teaching nexus in physics: scholarship into teaching and learning, Aust. Fam. Physician 44, 66 (2007).
${ }^{39}$ M. D. Sharma, J. Khachan, B. Chan, and J. W. O’Byrne, An investigation of the effectiveness of electronic classroom communication systems in large lecture classes, Aust. J. Eng. Educ. 21, 137 (2005).

${ }^{40} \mathrm{~J}$. Tuminaro and E. F. Redish, Elements of a cognitive model of physics problem solving: Epistemic games, Phys. Rev. ST Phys. Educ. Res. 3, 020101 (2007).

${ }^{41}$ D. E. Pritchard and Y.-J. Lee, Mathematical learning models that depend on prior knowledge and instructional strategies, Phys. Rev. ST Phys. Educ. Res. 4, 010109 (2008).

${ }^{42}$ A. L. Roberts, M. D. Sharma, S. Britton, and P. B. New, An index to measure the ability of first year science students to transfer mathematics, Int. J. Math. Educ. Sci. Technol. 38, 429 (2007).

${ }^{43}$ J. Cohen, Statistical Power Analysis for the Behavioural Sciences (Erlbaum, New York, 1988).

${ }^{44}$ R. K. Thornton and D. R. Sokoloff, Assessing student learning of Newton's laws: The Force and Motion Conceptual Evaluation and the Evaluation of Active learning Laboratory and Lecture Curricula, Am. J. Phys. 66, 338 (1998). 